cannot happen. A doctor or nurse will tell you when you can eat and drink, but this will not be until after the operation.

Usually about an hour before the operation you will be given an injection known as the premedication, or "premed." It will help to relax and make you feel sleepy before you are anaesthetised, so that the anaesthetic is easier and safer to administer. This injection is usually given into the buttock or leg, and once it is given you must stay in bed because it will make you drowsy. It may also make your mouth dry, but on no account must any drink be taken. Many people do not remember being taken to the operating theatre because the premed has made them so sleepy. Should you be awake, however, you may be surprised to find everyone dressed in gowns, boots, and hats. This helps prevent bacteria being brought into theatre. The anaesthetic is nearly always administered into a vein in the back of the arm or hand, and within about 10 seconds you are asleep. The doctor who puts you to sleep stays to look after you during the operation, so there is no danger of you waking up in the middle.
After the operation

After the operation you will be taken to a room called "recovery," where a nurse stays with you until you wake up. Once you are awake a nurse from your ward will come and collect you and take you back to your bed. Pain relievers will be administered if you want them, and you will be allowed to sleep. A nurse will come regularly to see how you are feeling and record your pulse and blood pressure, so don't worry if she seems to be coming a lot: it's routine after an operation.

The day after your operation it is usual to try and get you moving, but this depends on the type of operation you have had. You may be up and walking the next day, since early mobilisation reduces the risk of certain complications.

This paper was written when I was a student nurse.

(Accepted 14 fune 1979)

\title{
Medical Controversies
}

\section{Which appliance or aid?}

\author{
W V JAMES, P V SCOTT, A J COLLIER
}

British Medical fournal, 1979, 2, 314-316

Mr W V James was asked by the $B M \mathcal{F}$ to present a case for a service providing comparative evaluation of expensive appliances and aids. His article, published below, was then sent to an anaesthetist and a deputy secretary of the Department of Health and Social Security, and all three met to discuss the topic with one of the $B M F$ medical editors, Dr Tony Smith, acting as chairman.

\section{Working paper}

The housewife has the benefit of a family at hand to perform comparative evaluation of items such as soups, toilet rolls, or soap, and she probably takes little heed of the advertising on the labels. When it comes to more expensive and infrequently bought items, she finds that home comparative evaluation is more difficult. Happily there is a consumer organisation to look after her interests, and it arranges trials of these more expensive items. The results of these comparative trials are available to her in Which? Through this magazine a consumer can see what is available for the needs, and the relative merits, demerits, and costs, and finally a "best bu," are suggested.

The consumer and prescriber of expensive appliances and aids does not have the benefit of a service providing comparative

\footnotetext{
Withers Orthopaedic Centre, Musgrave Park Hospital, Belfast BT8 TJB

W V JAMES, FRCS, consultant orthopaedic surgeon

Bromsgrove General Hospital, Bromsgrove

P V SCOTT, MB, FFARCs, consultant anaesthetist

Department of Health and Social Security, London SE1 6BY

A J COLLIER, CB, deputy secretary
}

evaluation in the United Kingdom, and he only rarely sees the results of independent trials of individual items. He has, therefore, to rely on the advertisements of those making the items, which often seem to omit details of defects, costs, and whether they are inferior to other products in the same category. In all fairness, it is difficult for a manufacturer of appliances and aids to get an independent comparative evaluation and to get the results published in a reputable journal.

Evaluation is not a simple matter, and comparative evaluation is even more difficult. In order to provide adequate results, there has to be an adequate series. In order to accumulate enough information in a reasonable time, it may be necessary to employ the services of several centres at the same time. The time factor is crucial, for otherwise a trial can drag on to the point where information gained is out of date. There are, in fact, relatively few centres in the United Kingdom that have the right clinical facilities, the right staff to perform an evaluation, and the right equipment. Some centres might be more suitable for certain trials than others. An essential factor in such multicentre trials is an independent team that selects suitable centres, evolves the protocol for the trial, and arranges and monitors the trial. Finally, the team produces an analysis of the results, and also a summary for distribution.

Even when the evaluation is completed, there are problems in getting the results to those concerned. The wide variety of specialties involved in prescribing appliances and aids means that the results should be published in a wide variety of journals, hardly any of whom would regard such articles as being of prime interest to them. The only journal common to all would be the British Medical fournal, but it is not designed to be the sole outlet for specialised information on appliances and aids. Prosthetics and Orthotics International is an excellent journal devoted to the problems of appliances and aids, but is relatively young and not yet widely read in the United Kingdom. The excellent series of booklets on Equipment for the Disabled provides much information on aids, but is not involved in evaluation or comparative evaluation. 
Research and development has produced great advances in orthotics in the last two decades, yet these advances have been slow to get through to the consumer because of the information block. Society is demanding more and better assistance from appliances and aids, and it is unfortunate that they gain much of their information from the media, which often tend to give an unbalanced view on new products, mostly based on manufacturers' estimates. It is unfortunate if the information is passed on before there has been independent evaluation and those prescribing have been informed of the results.

The provision of drugs is also a multimillion pound exercise and has the benefit of an independent evaluation organisation. It also has the Drug and Therapeutics Bulletin (published by Which?) and the Prescribers' fournal that pass on information on the results of trials and of the comparative evaluation of drugs. For a modest sum, an independent organisation could be set up to evaluate appliances and aids, and to pass this information to the prescriber. Manufacturers would also welcome such an organisation to assist them in developing their products and ensure that they were brought to the notice of those that would prescribe them.

\section{Discussion}

MR W V JAMES: My basic premise is that doctors usually order equipment, including prostheses, orthoses, and aids on the recommendation of manufacturers-simply because they do not have the benefit of advice from evaluating committees. The manufacturers' information rarely makes any mention of cost, and indeed it may prove very difficult to get prices from the suppliers.

Furthermore, even when specialist units do set up projects to evaluate new devices the time taken may be such that the information becomes available only when it is out of date.

Chalrman: Is it in fact true that equipment does become out of date as quickly as that ? Are we not persuaded too easily that we must have the latest apparatus? Dr Scott, do you think anaesthetists like climbing on to fashionable bandwagons?

DR P V ScotT: Yes, I'm sure they do-which makes it all the more important that they should have access to the right sort of information. In my own hospital we do not get very much money to buy equipment, so it is terribly important that we spend it properly. What we need to know first of all is what is available; how much it costs and how much it costs to run; who is going to maintain it; and can it be run by the doctors? I am simply a doctor and it is all I can do to keep up with my specialty looking after patients. I haven't got the time to wonder what's inside the black box. What I want is a black box with a knob on it that does what I say.

ChaIRMan: In that case why insist upon retaining the right to choose which black box you're going to have? Why couldn't we have a system in which (say at the regional level) someone trained in making an assessment of the merits of the little black boxes available chooses which is the best?

DR ScotT: Frankly, I would go along with that if I could trust the persons doing the assessment-and provided that some allowance was made for the different needs of different types of hospital. However, many of my colleagues would disagree: there is still a strong emotional commitment to the concept of choice as a part of clinical freedom.

\section{Limited lists}

Mr A J Collier: I got into a certain amount of trouble at one stage in the past because I argued the case for a "limited list" approach-which implied a constraint on clinicians. Now while I do not think it is right that a doctor should be free to buy whatever he wants regardless of other considerations there is a risk when he is restricted to choosing from the six rated as best by an advisory group. Central decision-making carries a danger of crowding out new developments. However, in practice there is not that much difference between saying to the clinical user: "Here are the six that we think best, these are their qualities, and we think that this is perhaps the best" on the one hand and saying "here are the six we have chosen, you must take one of them." The difference is in the reaction you get from doctors if you tell them they must buy from the list of six. There is nothing absolute about cost or quality and very often a machine that is a bit more expensive may have a lot more value.

There are two ways of making an assessment of the range of apparatus available for a specific task. Firstly, clinicians might have access to some body which would offer to make the judgment in the way that Which? magazine does for washing machines. Which? often concludes that one model is, say, $50 \%$ more expensive but that it really is not that much better. The other way is for the assessment organisation simply to list the qualities in which one machine is better than another-and the costs-and then leave the judgment to the individual. The DHSS has launched comparative evaluations of cardiac monitors, defibrillators, ECGs, and diathermy apparatus at four centres including 11 hospitals. This comparative programme will continue with other equipment, and with technical evaluations as well as assessments of clinical preferences. The Department is also funding a multidisciplinary evaluation centre for $x$-ray equipment at King's College Hospital.

MR JAMES: My reaction to any sort of assessment of that kind would very much depend on who said it. If it was a committee of practising clinicians who understood my problems I would listen very carefully. On the other hand I would be less interested in a technical assessment of equipment by people who simply say it is "up to specification" and no more.

MR COLLIER: As you said in your paper, Mr James, it is very difficult to get enough expertise to do the work quickly enough. I agree that at present evaluation of, say, an electrocardiograph starts off with safety and goes on to technical details of performance as compared with the manufacturer's specification. Only then is any attempt made to say what the reaction is of someone actually using the machine. The constraint that operates in practice is that evaluations are most easily done by a group at a particular hospital or a laboratory with consultants who know the laboratory and are known to it. In other words you get one hospital or one clinical laboratory (or perhaps two or three) acquiring expertise at evaluation. Should we then have a specialist committee to go over the work again, or would it be enough for that committee to say: we know that unit, it is a good place, and we know $\mathrm{Mr}$ so and so and his colleagues and we will trust his judgment. One of the best ways of tapping the experience of a "committee of practising clinicians" is to involve doctors in the drawing up of standards for medical equipment. Ideally, these standards represent the agreed clinical requirements described in a technical way so that the hard and tedious job of testing can then be done by technicians rather than doctors. We are trying to evaluate against national and better still, international standards rather than the manufacturer's specification.

MR JAMES: No, I think the approach should be different. For example, the Committee for Prosthetics Research and Development in Washington (which has now sadly disappeared) used to organise good multicentre trials by first of all setting out in detail what the trial protocol should be. The objection to concentrating on one hospital unit is that the number of cases seen in one year may be very limited. I think you must have a time limit on these trials-and that means using several hospital units in order to get a good number of cases in as short a time as possible.

\section{Two problems}

CHAIRMAN: On the one hand we're talking about prostheses, and in some ways they rather resemble drugs in that only after you've put 10000 into 10000 patients would you really be in a 
position to say what are the rare but important things that can go wrong. It isn't quite the same when looking at pieces of fairly complex apparatus in use, say, by an anaesthetist where there won't be that many anyway and where quirks developed by one machine may not necessarily be a fault in the design but may be a fault in that individual machine. So that as far as machinery is concerned a really competent assessment in one or two units may be all that is required; whereas pieces of hardware used in a clinical setting do, I think, need a far wider kind of trial.

MR JAMES: Mr Collier, you said that if comparative assessments were done on an official basis there would probably be constraints on the availability of suitable units-and there remains the problem of communicating the results. If, however, there was an independent organisation with clinical and technical expertise to organise and supervise multicentre trials, the final result would be clinically orientated and rapid, and I am sure that the organisation would ensure that the results would be propagated.

DR ScotT: Often in Which? consumers themselves send in the reports. Someone may write and say "I've used this toothbrush for 10 years and its bristles are still as good as new." I believe that we could ask clinicians to do the same sort of thing.

MR JAMES: The first step might be to carry out a survey to see what is available. Some units are best geared to electronic measurements, others are better suited to production of standard appliances and things like that. Some have an academic approach and some a clinical approach.

MR Collier: It does seem from our experience so far that serious evaluation is a pretty specialised job-even the technical evaluation. When we are talking about evaluation in use by clinicians considerable effort is required.

DR Scotr: So long as these arrangements do not exist clinicians can hardly be blamed for buying expensive pieces of equipment when they are unaware of cheaper alternatives. Furthermore, it seems reasonable to make provision in the budget of district or area health authorities for the replacement of equipment and for the purchase of new equipment, but this is very seldom done. If I knew that every year there would be a certain proportion of the budget to spend on equipment I would get down to it and think about it very seriously. The way it works at the moment is that half way through the year someone will say "Look, you've got $£ 25000$ for equipment." That's not the way to run a health service.
Chairman: It's also, of course, true that if an authority earmarks money for buying equipment then that money will quite certainly be spent whether in fact equipment needs to be replaced that year or not.

Mr Collier: On the question of earmarking the problem is that a case may be made for allocating specific sums to an enormous range or purposes. If we had a few more people here to press their own claims the numbers would increase geometrically. There is a good case for earmarking so much on maintenance-just ordinary maintenance of buildings. Then there are clinical services that authorities don't like doingfamily planning, for example. There is no doubt that an agreed or rolling programme of equipment purchase and replacement is essential. It's just good management. It's a great pity there is not more of it.

DR SCOTT: Even when an allocation is made, however, the next step is a whole lot of doctors round a table excited and fighting one another for money. Now this is ideal from the DHSS point of view-doctors fighting doctors. We should be fighting the Department of Health.

MR Collier: But it really is not ideal. I think it is bad from every point of view.

DR ScotT: It is no answer to say that it is up to a hospital medical executive committee to make the final decision. Is a medical executive committee qualified to distinguish between a fibreoptic gastroscope for a surgeon and a new ventilator for an anaesthetist?

Mr Collier: Somebody is making those distinctions, aren't they ? Even in the best regulated world choices have to be made between the different departments and I do not think there is any kind of objective formula for doing so.

Mr JAMES: This is not only a problem of the Health Service: it happens with every hospital in the world.

Chairman: What is, in fact, done in other countries? Do the methodical Swedes, for example, have a system for assessing apparatus ?

Mr Collier: No; they have come to us to find out how we do evaluations. The Dutch have a laboratory that carries out evaluations from a technical point of view but we believe that ours is the largest organised evaluation programme in the world with about $£ \frac{3}{4}$ per year being spent. Our journal Health Equipment Information has carried 22 evaluation reports in the last two years.
$A$ healthy woman of 50 with no urinary symptoms has noticed that her urine has begun to smell extremely offensive over the past two months. Microscopic and bacteriological examination of the urine has failed to show any abnormality for this. What might be the cause?

The description "extremely offensive" is a relative one. Once the patient had noted a smell she would tend to look for it. The fact that results of microscopic and bacteriological examinations have been negative would seem to rule out the common Escherichia coli and the well-known "fishy" odours. The $\mathrm{pH}$ of fresh urine should be checked from time to time; inevitable ammoniation of urine confers its own smell. The presence of tiny amounts of protein is not abnormal (in the absence of red blood cells) at this age, and mild degradations of protein in alkaline urine may yield a putrefactive odour. The most likely cause is dietary habit and preference. Thus spinach eaters excrete a urine with a slightly acrid smell; habitual mushroom eating results in urine with a slightly fetid odour; and truffle eating confers a "stagnant" smell. Cold meats containing preservatives such as benzoates and nitrites may result in strange odours of the urine-for instance, corned beef eating is associated with urines that have variously been described as smelling of boot polish or metal polish. Obvious foods such as garlic sausage and patés (with or without anchovy supplements) yield typical odours that vary according to the $\mathrm{pH}$ of the urine. Many soups are fortified with glutamate that, in some people, may give "ammonia-like" smells. Less commonly, some people appear to absorb small quantities of the various ingredients of deodorants used for cosmetics and some of the basic, slightly unpleasant, fillers (and alcohols) may appear as traces in urine, as also do the perfumed components of talcum powder. Finally, if the patient is taking any multivitamin preparations one should consider if these are high in yeasts or vitamin B components that will impart a characteristic odour to urine.

My wife and I will be attending the BMA meeting in Hong Kong, and continuing to China. We had thought of taking a small dose of suphaguanidine and a tablet of metronidazole each day. Is this advisable, and what else in the way of immunisations and drugs are recommended?

For those who contemplate travelling in China, small daily doses of sulphaguanidine and metronidazole are unlikely to be of much value. At the onset of vomiting and diarrhoea it is advisable to give up eating all solid food for $\mathbf{2 4}$ hours, rest in the hotel, and drink plenty of boiled water, which is generously supplied in Thermos flasks left in the bedrooms for making Chinese tea; tap water should be avoided at all times. Codeine phosphate, $30 \mathrm{mg}$ four times daily, helps control diarrhoea and antibiotics are rarely needed. There are generally no facilities for the bacteriological examination of faeces unless the illness is bad enough for the patient to need admission to hospital. As to immunisations, only smallpox vaccination is required by international regulations. It is always sensible, however, to have had typhoid, cholera, tetanus, and poliomyelitis prophylaxis. A supply of a broadspectrum antibiotic, some travel sickness tablets, simple analgesics, and non-barbiturate hypnotics have generally proved quite adequate for most visitors to China. 